\title{
Surface active agent production from olive oil in high salt conditions and its process optimization
}

\author{
Mojtaba Taran', Elham Mohamadian', Sahand Asadi², Salar Bakhtiyari ${ }^{3,4 *}$ \\ ${ }^{1}$ Razi University, Department of Biology, Faculty of Science, Kermanshah, Iran \\ ${ }^{2}$ Islamic Azad University, Young Researchers Club, Kermanshah Branch, Kermanshah, Iran \\ ${ }^{3}$ Ilam University of Medical Sciences, Department of Clinical Biochemistry, School of Paramedicine, Ilam, Iran \\ ${ }^{4}$ Ilam University of Medical Sciences, Department of Clinical Biochemistry, School of Medicine, Ilam, Iran \\ *Corresponding author: e-mail: bakhtiyari-s@medilam.ac.ir,bakhtiyaribio@gmail.com
}

\begin{abstract}
Microbial surfactants or biosurfactants are surface active amphiphilic macromolecules that are produced by a number of microorganisms (bacteria, yeast and fungi). These compounds have extensive application in various industries especially in food, pharmaceutical and oil industry. The aim of this paper is to optimize the culture conditions for the biosurfactant production from olive oil by a novel halophilic isolate microorganism. The Taguchi experimental design methodology based analysis of olive oil as carbon source, yeast extract as nitrogen source and $\mathrm{KH}_{2} \mathrm{PO}_{4}$ as phosphorus source revealed that the olive oil and yeast extract significantly affect biosurfactant production in high salt conditions. Maximum biosurfactant $\left(\mathrm{E}_{24}=40 \%\right)$ produced in the presence of $4 \%(\mathrm{v} / \mathrm{v})$ olive oil, $0.2 \%(\mathrm{w} / \mathrm{v})$ yeast extract, and $0.002 \%(\mathrm{w} / \mathrm{v}) \mathrm{KH}_{2} \mathrm{PO}_{4}$. In conclusion, halophilic archaeon Haloarcula sp. IRU1 could be a potential microorganism for the production of biosurfactant from olive oil as carbon source in high salt conditions. The optimal parameters obtained during the optimization process were: olive oil $4 \%$, yeast extract $0.4 \%$ and $\mathrm{KH}_{2} \mathrm{PO}_{4} 0.004 \%$.
\end{abstract}

Keywords: Surface active agent, Olive oil, optimization, Taguchi experimental design methodology.

\section{INTRODUCTION}

Surfactants or surface active agents are widely used in the petroleum, pharmaceutical, cosmetic and food industries. Most of these compounds are chemically synthesized and it is only in the past few decades that surface-active molecules of biological origin have been described ${ }^{1}$. Biosurfactants are surfactants produced by microorganisms, either directly in microbial cell surfaces or by extracellular secretion. As amphiphilic molecules, biosurfactants contain hydrophilic and hydrophobic portions, and their structures are typically composed of one or more classes of compounds, including mycolic acids, glycolipids, polysaccharide-lipid complexes, lipoproteins, lipopeptides, phospholipids, and/or the microbial cell surface itself ${ }^{2-4}$.These microbial compounds have extensive application in various industries, mining, leather, agricultural, oil recovery with functional properties as foaming, surface activity, wetting agent, emulsification in agricultural, pharmaceutical, cosmetics and a wide range of petrochemical industries ${ }^{5}$. They can be active at extremes of temperature, $\mathrm{pH}$, and salinity and can be synthesized from renewable feedstocks besides, making an ecofriendly environment ${ }^{6-10}$. The type, effectiveness, and efficiency of biosurfactants are influenced by the nature of the carbon sources and the concentrations of nitrogen, phosphorus, magnesium, iron, and sulfur ions in the medium ${ }^{6}$. The search for biosurfactants in extremophiles seems to be particularly promising since the biosurfactants of these organisms have particular adaptations to increase stability in adverse environments that can potentially increase their stability in the harsh environments in which they are to be applied in biotechnology ${ }^{11,12}$.

Halophiles, which have a unique lipid composition (phytanylglycerol), may have an important role to play as surface-active agents. The archae bacterial ether-linked phytanyl membrane lipid of the extremely halophilic bacteria has been shown to have surfactant properties ${ }^{12}$. Yakimov et al. reported the production of biosurfactant by a halotolerant Bacillus species and its potential in enhanced oil recovery. In that study, Bacillus licheniformis strain BAS 50 was able to grow and produce a lipopeptide surfactant in different salinities ${ }^{13}$. In the present study, we aimed to optimize for the first time, the culture medium composition for the biosurfactant production from olive oil by a novel halophilic isolate Haloarcula sp. IRU1 using Taguchi experimental design methodology.

\section{EXPERIMENTAL}

\section{Microorganism, Growth Medium and Culture Conditions}

Haloarcula sp. IRU1 isolated from hypersaline Lake Urmia, Iran was cultured in $50 \mathrm{~mL}$ liquid basal salt medium composed of $(\mathrm{g} / \mathrm{L})$ : $\mathrm{NaCl}, 250 ; \mathrm{MgCl}_{2} .6 \mathrm{H}_{2} \mathrm{O}, 34.6$; $\mathrm{MgSO}_{4} .7 \mathrm{H}_{2} \mathrm{O}, 49.4 ; \mathrm{CaCl}_{2} .2 \mathrm{H}_{2} \mathrm{O}, 0.92 ; \mathrm{NaBr}, 0.058 ; \mathrm{KCl}$, $0.5 ; \mathrm{NaH}_{2} \mathrm{CO}_{3}, 0.17$. The growth medium supplemented with various nutrients compositions by varying olive oil as carbon source at $0.5-4 \%(\mathrm{v} / \mathrm{v})$, yeast extract as nitrogen source at $0.05-0.4 \%(\mathrm{w} / \mathrm{v})$ and $\mathrm{KH}_{2} \mathrm{PO}_{4}$ as phosphorus source at $0.001-0.008 \%(\mathrm{w} / \mathrm{v})$ according to the details following the experiment design (Table 1 and 2). The cultivation temperature for all experiments was $42^{\circ} \mathrm{C}$.

\section{Emulsification activity assay}

After 5 days of incubation in an orbital shaker at 200 $\mathrm{rpm}$ and $42^{\circ} \mathrm{C}$, the cells were removed by centrifugation

Table 1. Parameters and levels used in this experiment

\begin{tabular}{|l|l|l|l|l|l|}
\hline Factor & Parameter & Level1 & Level2 & Level3 & Level4 \\
\hline Factor A & Olive oil \% (V/V) & 0.5 & 1 & 2 & 4 \\
\hline Factor B & Yeast extract \% (W/V) & 0.05 & 0.1 & 0.2 & 0.4 \\
\hline Factor C & $\mathrm{KH}_{2} \mathrm{PO}_{4} \%(\mathrm{~W} / \mathrm{V})$ & 0.001 & 0.002 & 0.004 & 0.008 \\
\hline
\end{tabular}


Table 2. Taguchi experimental design for three variables affecting biosurfactant productionby Haloarcula sp. IRU1

\begin{tabular}{|l|c|c|c|c|}
\hline Trial & Olive oil \% (V/V) & $\begin{array}{c}\text { Yeast extract } \\
\%(\mathrm{~W} / \mathrm{V})\end{array}$ & $\mathrm{KH}_{2} \mathrm{PO}_{4} \%(\mathrm{~W} / \mathrm{V})$ & $\mathrm{E}_{24}(\%)$ \\
\hline 1 & 0.5 & 0.05 & 0.001 & 13.33 \\
\hline 2 & 0.5 & 0.1 & 0.002 & 20.00 \\
\hline 3 & 0.5 & 0.2 & 0.004 & 28.33 \\
\hline 4 & 0.5 & 0.4 & 0.008 & 31.67 \\
\hline 5 & 1 & 0.05 & 0.002 & 21.67 \\
\hline 6 & 1 & 0.1 & 0.001 & 18.33 \\
\hline 7 & 1 & 0.2 & 0.008 & 25.00 \\
\hline 8 & 1 & 0.4 & 0.004 & 33.33 \\
\hline 9 & 2 & 0.05 & 0.004 & 23.33 \\
\hline 10 & 2 & 0.1 & 0.001 & 26.67 \\
\hline 11 & 2 & 0.2 & 0.008 & 30.00 \\
\hline 12 & 2 & 0.4 & 0.002 & 36.67 \\
\hline 13 & 4 & 0.05 & 0.008 & 28.33 \\
\hline 14 & 4 & 0.1 & 0.004 & 35.00 \\
\hline 15 & 4 & 0.2 & 0.002 & 40.00 \\
\hline 16 & 4 & 0.4 & 0.001 & 38.33 \\
\hline
\end{tabular}

at $10000 \mathrm{rpm}$ for $10 \mathrm{~min}$ at room temperature. Two milliliters of the cell-free supernatant was mixed with 2 $\mathrm{ml}$ kerosene in a test tube. This mixture was shaken for $2 \mathrm{~min}$ and then left to stand. The emulsification stability was measured after $24 \mathrm{~h}$ and the emulsification index $\left(E_{24}\right)$ was calculated by dividing the measured height of the emulsion layer by the total height of the liquid layer and multiplying by $100^{\mathbf{1 1}, 14}$.

\section{Experimental design and statistical analyses}

Taguchi experimental method was used to describe the number of experimental situations. All experiments were preformed in $250 \mathrm{ml}$ Erlenmeyer flasks containing $50 \mathrm{ml}$ of the basal medium and incubated in a shaker at $42^{\circ} \mathrm{C}$ and $200 \mathrm{rpm}$ for 5 days. The culture broth was separated and analyzed for biosurfactant. Qualitek-4 software was used for the design and analysis of Taguchi experiments.

\section{RESULTS AND DISCUSSION}

The Taguchi experimental design differentiates between control factors and the noise or uncontrollable factors, and treats them separately by means of special design matrices called "Orthogonal Arrays"(OA). Columns and rows of an OA are arranged in a fixed way indicating the combination of factor levels in each experiment to be run, and allowing the simultaneous evaluation of several parameters with the minimum number of trials ${ }^{\mathbf{1 5 , 1 6}}$. The Taguchi experimental design is a good positive option for the optimization of biotechnological processes for microbial synthesis ${ }^{17}$. The effect of olive oil as carbon source, $\mathrm{KH}_{2} \mathrm{PO}_{4}$ as phosphorus source, yeast extract as nitrogen source on the biosurfactant production by Haloarcula sp. IRU1 was tested in the Taguchi experimental design that resulted in a total of 16 experiments. Based on the experimental design, the factor combinations resulted in different biosutfactant amounts. The range of the responses was $40 \%$ in experiment No. 15 (maximum) and $13.3 \%$ in experiment No. 1 (minimum). The results indicated that Haloarcula sp. IRU1 gave highest biosutfactant $\left(E_{24}=40 \%\right)$ in the presence of $4 \%(\mathrm{v} / \mathrm{v})$ olive oil, $0.2 \%(\mathrm{w} / \mathrm{v})$ yeast extract, and $0.002 \%(\mathrm{w} / \mathrm{v})$ $\mathrm{KH}_{2} \mathrm{PO}_{4}$ (Table 2).

\section{Effect of carbon source}

Olive oil has been suggested to be one of the best carbon sources for biosurfactant synthesis ${ }^{\mathbf{1 8}}$. The effect of olive oil concentration on biosurfactant production was evaluated at $42^{\circ} \mathrm{C}$ varying olive oil of $0.5,1,2$, and $4 \%(\mathrm{v} / \mathrm{v})$. The kinetic curves obtained at this step are presented in Fig. 1. Using different concentrations of olive oil we can observe that biosurfactant was produced. Using $0.5 \%$ of olive oil in a different experiment, lower biosurfactant production was obtained. The highest production in these experimental conditions was obtained only using $4 \%$ of olive oil. From Fig. 1, it can be verified that when olive oil concentration is increased from 0.5 to $4 \%$, the biosurfactant increased from $23.3 \%$ to $35.4 \%$. Then olive oil concentration has a significant effect on biosurfactant production. A possible explanation for this fact might be related to the fact that microbial ability to synthesize biosurfactant is often coupled with their ability to grow on immiscible carbon sources, such as hydrocarbons. Biosurfactants have been demonstrated to play a role in different stages of the interaction between microorganisms and hydrocarbons by overcoming the low solubility of these substrates, accessing to hydrocarbons before transportation into cells, and regulating the adhesion-deadhesion of microbial cells from and to hydrocarbon surfaces ${ }^{19,20}$.

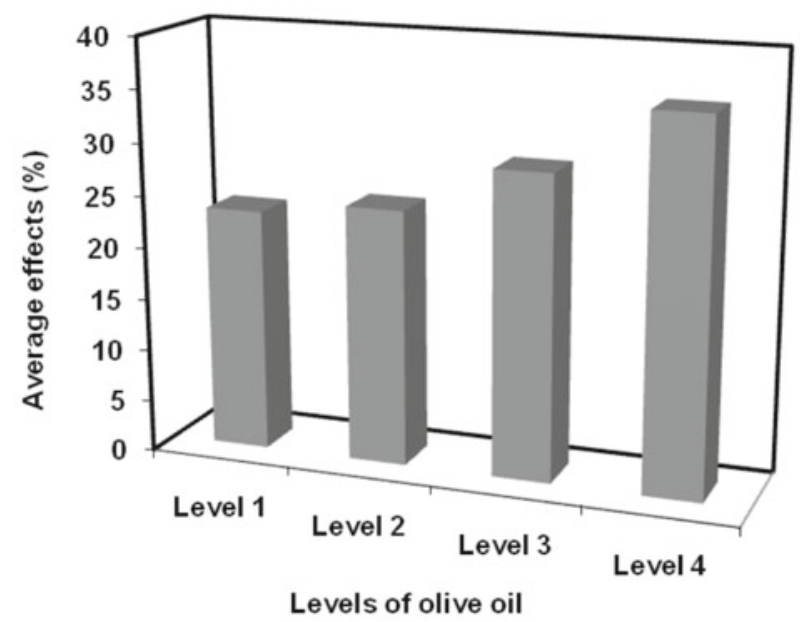

Figure 1. Average effects of olive oil on biosurfactant production obtained by Qualitek-4 (W32b) software

\section{Effect of nitrogen source}

The effect of four yeast extract concentrations $(0.05$, $0.1,0.2$, and $0.4 \%$ ) on the level of biosurfactant produced by Haloarcula sp. IRU1 is presented in Fig.2. The increase in yeast extract concentration caused the increase in the amount of biosurfactant produced by Haloarcula sp. IRU1. Studying the different concentrations of yeast extract we found that the highest concentration $(0.4 \%)$ was the best concentration for the production of Biosurfactant (Fig.2). Nitrogen source plays an important role in the production of biosurfactant by microorganisms ${ }^{\mathbf{1 4}}$. It has been reported that the type of nitrogen influenced 


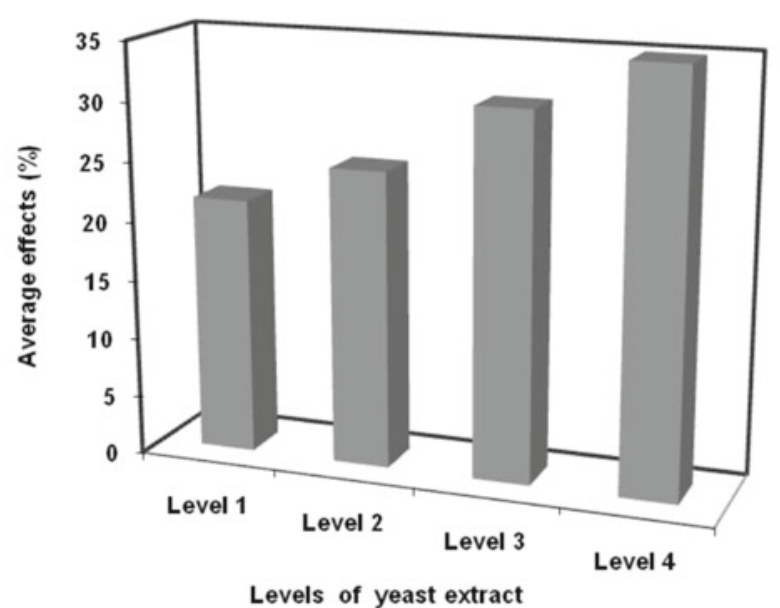

Figure 2. Average effects of yeast extract on biosurfactant production obtained by Qualitek-4 (W32b) software the biosurfactant produced by microorganisms. ${ }^{21}$ Previous studies have reported that the enhancement of nitrogen concentration increased the microbial biosurfactant production $^{6,21,22}$.

\section{Effect of phosphorus source}

When measure $\mathrm{E}_{24}$ for the produced biosurfactant in different concentrations of $\mathrm{KH}_{2} \mathrm{PO}_{4}(0.001,0.002,0.004$, $0.008 \%$ ) we found that concentration $0.004 \%$ was the best for biosurfactant production (Fig.3). An increase in the concentration of phosphorus source in the medium for the production of biosurfactant was not associated with any remarkable changes in the biosurfactant production. Some studies have reported that the enhancement of phosphorus concentration did not significantly increase the microbial biosurfactant production ${ }^{6}$.

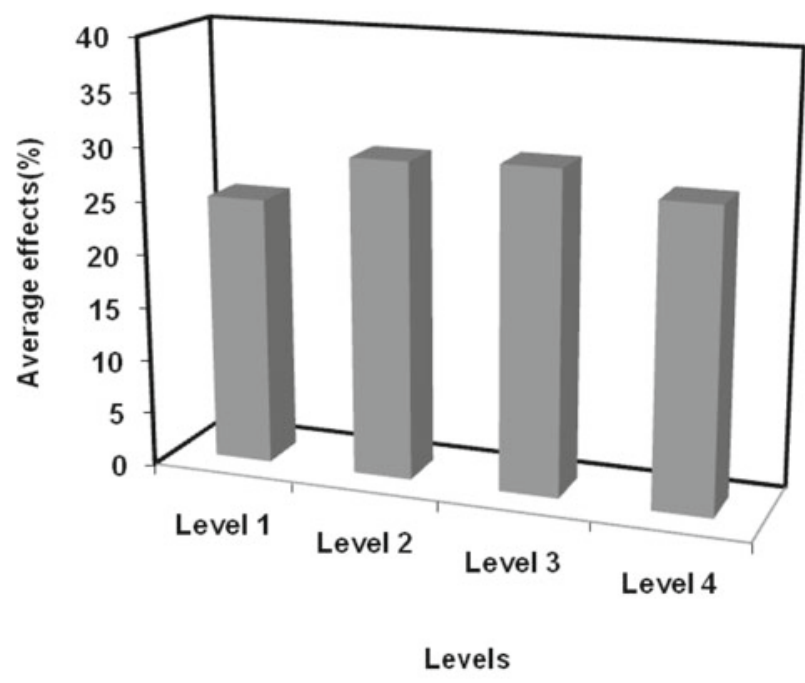

Figure 3. Average effects of $\mathrm{KH}_{2} \mathrm{PO}_{4}$ on biosurfactant production obtained by Qualitek-4 (W32b) software

\section{Analysis of variance}

The purpose of the analysis of variance (ANOVA) for orthogonal array is to determine which process factors significantly affect the yield. There is a tool called an $F$-test to see which process factors have a significant effect on the quality characteristic. In performing the $F$-test, the mean of squared deviation due to each factor needs to be calculated. The $F$-test value for each factor is simply the ratio of the mean of squared Deviation to the mean of squared pooled error. The process factors with a large $F$-test value have a more significant effect on the quality characteristic. In addition, for significant factors their percentage contributions can be determined from the mean of squared pooled error and the pure sum of squared deviation due to each factor ${ }^{23-25}$. Table 3 shows the results of ANOVA for biosurfactant production by Haloarcula sp. IRU1. The last column of the table shows the percentage contribution of each factor on the total variation which indicates the degree of influence on the yield of biosurfactant. The percentage contributions, sum of squares and maximum variances of parameters affecting the yield of biosurfactant in a decreasing order are: yeast extract $(39.77,391.02$ and 130.43 respectively), olive oil (36.07, 358.99 and 119.66 respectively), $\mathrm{KH}_{2} \mathrm{PO}_{4}$ (5.94, 61.848 and 5.94 respectively). From ANOVA, it is clear that nitrogen source (yeast extract) is the most significant process factor affecting biosurfactant production, followed by the carbon source (olive oil). The change of phosphorus source $\left(\mathrm{KH}_{2} \mathrm{PO}_{4}\right)$ in the range tested $(0.001-0.008 \%)$ has little effect on biosurfactant.

\section{Optimization of parameters using Taguchi's approach}

Table 4 shows a predicted yield of biosurfactant produced by Haloarcula sp. IRU1 under optimal conditions for process parameters. By using the optimization function of the Taguchi experimental design the maximum yield of biosurfactant $\left(\mathrm{E}_{24}=42.50 \%\right)$ was predicted at a reaction condition of olive oil $4 \%$, yeast extract $0.4 \%$, $\mathrm{KH}_{2} \mathrm{PO}_{4} 0.004 \%$. Good agreement is observed between the predicted value and experimental value of $E_{24}$. It can also be seen that the yield of biosurfactant under optimal conditions for factor levels is higher than any of the experimental yields shown in Table 2 .

The contribution of the tested factors in biosurfactant production by Taguchi experimental design showed that olive oil played a more important role than the other

Table 4. Prediction of optimum conditions for biosurfactant production Haloarcula sp. IRU1

\begin{tabular}{l|c|c|c|}
\hline Factors & Level Description & Level & Contribution \\
\hline Olive oil & $4 \%$ & 4 & 7.29 \\
\hline Yeast extract & $0.4 \%$ & 4 & 5.208 \\
\hline $\mathrm{KH}_{2} \mathrm{PO}_{4}$ & $0.004 \%$ & 3 & 1.873 \\
\hline Total Contribution From All Factors \\
Current Grand average Of Performance \\
Expected Results At Optimum Condition
\end{tabular}

Table 3. Analysis of Variance (ANOVA) for biosurfactant production Haloarcula sp. IRU1

\begin{tabular}{|l|c|c|c|c|c|}
\hline Factors & $\begin{array}{c}\text { DOF } \\
(f)\end{array}$ & Sum of Sqrs (S) & Variance (V) & F-Ratio (F) & Pure Sum (S') \\
\hline Olive oil & 3 & 358.993 & 119.664 & 7.705 & 312.404 \\
\hline Yeast extract & 3 & 391.023 & 130.341 & 8.393 & 344.435 \\
\hline $\mathrm{KH}_{2} \mathrm{PO}_{4}$ & 3 & 22.896 & 7.632 & 0.491 & 36.07 \\
\hline
\end{tabular}


factors. The contributions of the parameters affecting the yield of biosurfactant in optimal conditions were: yeast extract (5.21), olive oil (7.29) and $\mathrm{KH}_{2} \mathrm{PO}_{4}$ (1.87). The total contribution and grand average performance from all factors were 14.37, 28.12 respectively.

\section{CONCLUSIONS}

In this work, we used Taguchi orthogonal array design method to optimize biosurfactant synthesis from olive oil by Haloarcula sp. IRU1. The following conclusions can be drawn based on the experimental results of this study:

- Taguchi methodology design is suitable to optimize the conditions for biosurfactant production by Haloarcula sp. IRU1.

- The yeast extract as nitrogen source and olive oil as carbon source significantly affect the biosurfactant production.

- The optimal levels of nitrogen source, carbon source and phosphorus source were estimated for the best biosurfactan production.

- The optimal conditions for biosurfactan production were: olive oil $4 \%$, yeast extract $0.4 \%, \mathrm{KH}_{2} \mathrm{PO}_{4} 0.004 \%$.

\section{Acknowledgements}

The authors gratefully acknowledge financial support from the Iran National Science Foundation (INSF) and Ilam University of Medical Sciences.

\section{LITERATURE CITED}

1. Onbasli, D. \& Aslim, B. (2009). Biosurfactant production in sugar beet molasses by some Pseudomonas spp, J. Environ. Biol., 30, 161-163.

2. Pacheco, G.J., Ciapina, E.M.P., Gomes, E.B. and Junior, N.P. (2010). Biosurfactant production by Rhodococcus erthropolis and its application to oil removal, Brazilian J. Microbiol., 41, 685-693.

3. Kumar, C.G., Joo, S.H., Choi, J.W., Koo, Y.M. \& Chang, C.S., (2004). Purification and characterization of an extracellular polysaccharide from haloakalophilic Bacillus sp. I-450. Enz. Microbial. Technol., 34, 673-681. doi:10.1016/j.enzmictec.2004.03.001.

4. Van Dyke, M.I., Lee, H. \& Trevors, J.T., (1991). Applications of Microbial Surfactants. Biotech. Adv., 9, 241\&252.

5. Parthasarathi, R. \& Sivakumaar, P.K. (2009). Effect of Different Carbon Sources on the Production of Biosurfactant by Pseudomonas fluorescens Isolated from Mangrove Forests (Pichavaram), Tamil Nadu, India. Glob.

J. Env. Res. 3, 99-101.

6. Pruthi, V. \& Cameotra, S.S., (2003). Effect of Nutrients on Optimal Production of Biosurfactants by Pseudomonas putida-A Gujarat Oil Field Isolate. J. Surfact. Deterg., 6, 65-68.

7. Zajic, J.E., Gignard, H. \& Gerson, D.F. (1997). Properties and Biodegradation of a Bioemulsifier from Corynebacterium hydrocarboclatus. Biotechnol. Bioeng., 19, 1303-1312.

8. Kretschmer, A., Bock, H. \& Wagner, F. (1982). Chemical and Physical Characterization of Interfacial-Active Lipids from Rhodococcus erythropolis Grown on n-Alkane. Appl. Environ. Microbiol. 44, 864-870.
9. Georgiou, G., Lin, S.C. \& Sharma, M.M. (1990). Surface Active Compounds from Microorganisms. BioTechnol., 10, 60-65.

10. Desai, J.D. \& Banat, I.M., (1997). Microbial Production of Biosurfactants and Their Commercial Potential, Microbiol. Mol. Biol. Rev. 61, 47-64.

11. Kebbouche-Gana, S., Gana, ML, Khemili, S., Fazouane-Naimi, F., Bouanane, N.A., Penninckx, M. \& Hacene, H., (2009). Isolation and characterization of halophilic Archaea able to produce biosurfactants, J. Ind. Microbiol. Biotechnol., 36, 727-738. DOI: 10.1007/ s10295-009-0545-8.

12. Post, F.J. \& Collins, N.F. (1982). A preliminary investigation of the membrane lipid of Halobacterium halobium as a food additive, J. Food. Biochem., 6, 25-38. DOI: 10.1111/j.1745-4514.1982.tb00294.x.

13. Yakimov, M.M., Timmis, K.N., Wray, V., \& Fredrickson, H.L., (1995). Characterization of a new lipopeptide surfactant produced by thermotolerant and halotolerant subsurface Bacillus licheniformis BAS 50, Appl. Environ. Microbiol., 61,1706-1713.

14. Kiran, G.S., Hema, T.A., Gandhimathi, R., Selvin, J., Thomas, T.A., Ravji, T.R. \& Natarajaseenivasan, K. (2009). Optimization and production of a biosurfactant from the sponge-associated marine fungus Aspergillus ustus MSF3, Col. Surf. B Biointer., 73, 250-256. doi:10.1016/j.colsurfb.2009.05.025.

15. Shyu, H.L. \& Hsieh, L.L. (2007). Application of the Taguchi experimental design to the optimization of $\mathrm{UV} / \mathrm{TiO} 2$ and $\mathrm{UV} / \mathrm{H}_{2} \mathrm{O}_{2}$ process for copper complexes treatment, Environ. Inform. Arch., 5, 674-683.

16. Taguchi, G. (1991). System of experimental design. Quality Resources, Kraus and Americans Supplier Institute (eds), USA.

17. Venil, C.K. \& Lakshmanaperumalsamy, P, (2008) Response Surface Methodology for the Optimization of Alpha Amylase Production by Serratia marcescens SB08, P. J. Sci. Technol. 51, 333-339.

18. Abouseoud, M., Maachi, R. \& Amrane, A. (2007). Biosurfactant Production from olive oil by Pseudomonas fluorescens. Comm. Cur. Res. Edu. Top. Trends Appl. Microbiol. 340-347.

19. Franzetti, A., Caredda, P., Colla, P.L., Pintus, M., Tamburini, E., Papacchini, M. \& Bestetti, G. (2009). Cultural factors affecting biosurfactant production by Gordonia sp. BS29, Int. Biodeter. Biodeg., 63, 943-947.

20. Van Hamme, J.D., Singh, A. \& Ward, O.P. (2006). Physiological aspects. Part 1 in a series of papers devoted to surfactants in microbiology and biotechnology, Biotechnol., Adv., 24, 604-620. doi:10.1016/j. biotechadv.2006.08.001.

21. Haba, E., Espuny, M.J., Busqueis, M., \& Manresa, A. (2000). Isolation of lipasescreening bacteria by developing used frying oil as selective substrate, J. Appl. Microbiol., 88, 379-387.

22. Moussa, TAA, Ahmed, G.M. \& Abdel-hamid, S.M.S., (2006) Optimization of Cultural Conditions for Biosurfactant Production from Nocardia amarae, J. Appl. Sci. Res., 2, 844-850.

23. Zhu, Y., Ni, J. \& Huang, W., (2010), Process optimization for the production of diosgenin with Trichoderma reesei, Bioproc. Biosyst. Eng., 33, 647-655.DOI: 10.1007/ s00449-009-0390-1. 
24. Wang, Y.X., Liu, H., Bao, J.G., Hong, Y., Yang, Z.H. \& Zhang, C.X. (2008). The saccharification-membrane retrieval-hydrolysis (SMRH) process: a novel approach for cleaner production of diosgenin derived from Dioscorea zingiberensis, J. Cleaner Prod., 16, 1133-1137. doi:10.1016/j.jclepro.2007.05.008.

25. Sheng, J., Chi, Z.M., Yan, K.R., Wang, X.H., Gong, F., \& Li, J., (2009). Use of response surface methodology for optimizing process parameters for high inulinase production by the marine yeast Cryptococcus aureus G7a in solid-state fermentation and hydrolysis of inulin. Bioproc. Biosyst. Eng., 32, 333-339. DOI: 10.1007/ s00449-008-0252-2. 